\title{
A new approach: Ischemic mitral regurgitation guidelines by and for surgeons
}

\author{
Patrick M. McCarthy, MD
}

\footnotetext{
From the Division of Cardiac Surgery, Department of Surgery, Northwestern University Feinberg School of Medicine, Northwestern University, Chicago, Ill.

Disclosures: P.M.M. receives financial compensation from Edwards Lifesciences (consultancy, royalties, and intellectual property) as the inventor of the Edwards MC3 Ring and dETlogix Ring and as the coinventor of the IMR ETlogix Ring and from Abbott Vascular (consultancy). Author has nothing additional to disclose with regard to commercial support.

Received for publication Sept 18, 2015; accepted for publication Sept 23, 2015.

Address for reprints: Patrick M. McCarthy, MD, Executive Director of the Bluhm Cardiovascular Institute, Chief of the Cardiac Surgery Division, Division of Cardiac Surgery, Heller-Sacks Professor of Surgery at the Northwestern University Feinberg School of Medicine, Northwestern University, 201 E Huron St, Suite 11-140, Chicago, IL 60611-2908 (E-mail: pmccart@nmh.org).

J Thorac Cardiovasc Surg 2016;151:957-8

$0022-5223 / \$ 36.00$

Copyright $@ 2016$ by The American Association for Thoracic Surgery

http://dx.doi.org/10.1016/j.jtcvs.2015.09.094
}

One of the more vexing problems for cardiac surgeons is how best to approach the patient with ischemic mitral regurgitation (IMR). Through the decades, we have been witness to many different surgical concepts, approaches, and especially opinions. We may encounter IMR in patients with advanced heart disease who seem to have no option other than cardiac transplant or ventricular assist device support; we may see IMR in symptom-free patients with an occluded coronary and no other indication for surgery; we may find IMR in patients with angina in the coronary care unit with 3-vessel disease and no previous infarction; or, perhaps most commonly in the surgical population in patients with IMR, we may find IMR associated with a reduced ejection fraction, significant coronary artery disease, atrial fibrillation, and tricuspid regurgitation. Confounding the decision making, imaging studies may grade the degree of mitral regurgitation at different levels depending on the loading conditions. There are questions about the proper surgical treatment of patients with IMR, such as whether the valve should be repaired or replaced, and if so, how; whether coronary arteries should be grafted; whether atrial fibrillation and tricuspid regurgitation should be treated; and whether to use the percutaneous therapies now approved in Europe and undergoing clinical trials in the United States. Finally, the valve leaflets themselves are typically normal, so fundamentally we are treating a ventricular problem, and there are a host of therapiesincluding medications, defibrillators, and biventricular synchronous pacing - that can, and should, be applied until the patient has received "optimal" medical therapy before surgery is considered.

Previous guidelines published by the American Heart Association and the European Society of Cardiology ${ }^{1,2}$ have given relatively little attention to IMR, in part because of the complicated clinical situations in which it

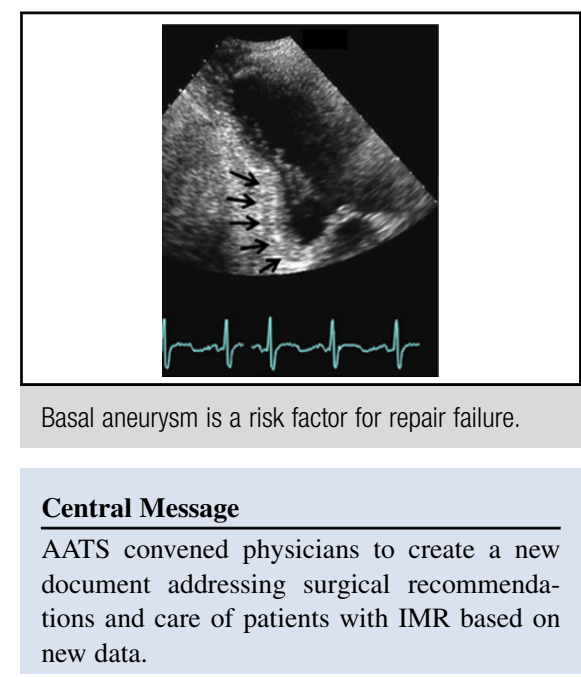

See Article page 940.

See Editorial page 906.

is encountered and in part because we do not have great data. For instance, the American Heart Association guidelines devoted only 2 pages to IMR in the most recent document of valve guidelines, a document 132 pages long. For perspective, they spent 11 pages discussing valve disease in pregnancy, which is a rare concern for the surgical community.

In compiling the guidelines appearing in this issue of the Journal, Kron and colleagues ${ }^{3}$ have accepted a daunting task. A team composed primarily of surgeons gathered to sift through the data, synthesize it into a document, and make coherent recommendations for surgeons, including how and when to repair the valve or replace it and a discussion of the role of percutaneous therapy. They provide a comprehensive review of the subject and up-todate references. Importantly, there will be more information coming from the longer-term follow-up of the CTSNet trials looking at the role of mitral repair in patients with moderate IMR undergoing coronary artery bypass grafting ${ }^{4}$ and whether to repair or replace valves in patients being treated with IMR. ${ }^{5}$ Surgical prospective trials are always much harder to execute than drug trials (in the repair vs replacement trial, less than $10 \%$ of the patients screened actually were randomly assigned), but the trials give us information that has not been readily available in previous studies. For instance, a quick glance at the repair versus 
replacement trial would indicate that clinical results are the same but there is more recurrent regurgitation in the group of patients with repair than in that with replacement. A more careful view, however, of the results may indicate that the old "truism" that a good repair is better than replacement, and both are better than a bad repair, may well turn out to be true with longer follow-up. The writing committee has made very specific recommendations about the role of repair and replacement for IMR, and their recommendations for surgery can be compared with the existing guidelines in Table 3 of the Kron document. The American Association for Thoracic Surgery guidelines for surgeons get "down in the weeds" and recommend replacement for patients with a basal aneurysm (dyskinesis), significant echocardiographic evidence of leaflet tethering, or moderate to severe left ventricular remodeling (left ventricular end-diastolic diameter $>65 \mathrm{~mm}$ ). They further recommend preserving both anterior and posterior cords during replacement. These are significant advances in our understanding of the surgical treatment of IMR. For years, we have known that severe tethering is one of the risk factors for repair failure. Going forward, we have 3 choices: to identify the patients before surgery who are at high risk for repair failure and treat those with a cord-sparing replacement; to come up with a better way to do repair (likely involving the subvalvular apparatus), such that the repair becomes durable; or just to replace all valves with IMR.
In summary, this is an interesting new approach to the guidelines for IMR. The level of granularity of the existing valve guidelines has been insufficient for practicing surgeons. This new document from the American Association for Thoracic Surgery should help surgeons sift through the competing studies and opinions and form a coherent approach. Of course, the approach may change when we have more information!

\section{References}

1. Nishimura RA, Otto CM, Bonow RO, Carabello BA, Erwin JP III, Guyton RA, et al; American College of Cardiology; American College of Cardiology/ American Heart Association; American Heart Association. 2014 AHA/ACC guideline for the management of patients with valvular heart disease: a report of the American College of Cardiology/American Heart Association Task Force on Practice Guidelines. J Thorac Cardiovasc Surg. 2014;148:e1-132. Erratum in: J Thorac Cardiovasc Surg. 2014;64:1763.

2. Vahanian A, Alfieri O, Andreotti F, Antunes MJ, Barón-Esquivias G, Baumgartner H, et al; Joint Task Force on the Management of Valvular Heart Disease of the European Society of Cardiology (ESC); European Association for Cardio-Thoracic Surgery (EACTS). Guidelines on the management of valvular heart disease (version 2012). Eur Heart J. 2012;33:2451-96.

3. Kron IL, Acker MA, Adams DH, Ailawadi G, Bolling SF, Hung JW, et al. 2015 The American Association for Thoracic Surgery Consensus Guidelines: Ischemic mitral valve regurgitation. J Thorac Cardiovasc Surg. 2016;151: 940-56.

4. Smith PK, Puskas JD, Ascheim DD, Voisine P, Gelijns AC, Moskowitz AJ, et al; Cardiothoracic Surgical Trials Network Investigators. Surgical treatment of moderate ischemic mitral regurgitation. N Engl J Med. 2014;371: 2178-88.

5. Acker MA, Parides MK, Perrault LP, Moskowitz AJ, Gelijns AC, Voisine P, et al; CTSN. Mitral-valve repair versus replacement for severe ischemic mitral regurgitation. N Engl J Med. 2014;370:23-32. 